some consumers because of the lower price differential.

- There could be legal liabilities for inadvertent (and inconsequential) errors in labeling.

- Companies that provide GE testing in the supply chain would experience a financial bonanza.

The evolution of markets in places such as the European Union, where GE-ingredient labeling has been mandatory for many years, shows that-contrary to the stated intentions of labeling initiatives (namely, to offer greater choice)—consumers are the principal losers, with less choice and higher prices. If one asks who benefits from mandatory GE labeling, it should not be surprising that the answer is the producers and purveyors of organic food, as well as those who perform tests for GE ingredients. They have spearheaded and funded the labeling initiatives in the United States and have made no secret of the fact that they regard labeling as the first necessary step toward the complete elimination of genetic engineering. For example, in an open letter (http://bit.ly/1FAdxA4), Ronnie Cummins, the director of the Organic Consumers Association, reveals the organic lobby's agenda clearly: "The burning question for us all then becomes how-and how quickly—can we move healthy, organic products from a $4.2 \%$ market niche to the dominant force in
American food and farming? The first step is to change our labeling laws."

Why such a relentless push for mandatory labeling of GE products? One motivation on the part of the organic and natural products industries may be a fear that the current gap between organic and conventional agriculture will become a chasm, as modern technologies and products that are unavailable to organic farmers become ever more efficient and productive (http://bit.ly/1EpQ9ZH). Continuing advances in genetic engineering and synthetic biology will potentially open up vast new vistas.

Motivations aside, mandatory labeling of GE products is a complex and potentially costly undertaking - and in the end, it is neither necessary nor advantageous to consumers.

COMPETING FINANCIAL INTERESTS

The authors declare no competing financial interests.

Graham Brookes ${ }^{1}$ \& Henry I Miller ${ }^{2}$

${ }^{1} P G$ Economics Limited, Dorchester, UK.

${ }^{2}$ Hoover Institution, Stanford University,

Stanford, California, USA.

e-mail:henry.miller@stanford.edu

1. Anonymous. Nat. Biotechnol. 32, 1169 (2014).

2. Brookes, G. \& Barfoot, P. GM Crops Food 5, 65-75 (2014).

3. Miller, H. \& Conko, G. Wall Street Journal. http://www. wsj.com/articles/SB1000142405270230404970457 9320311512770326 (2014).

4. Scherer, L.D., Maynard, A., Dolinoy, D.C., Fagerlin, A. \& Zikmund-Fisher, B.J. Health Risk Soc. 16, 649-666 (2014).

\title{
Transparency in GM food labeling
}

To the Editor:

I am writing in response to the Editorial in the December issue entitled "Label without a cause," ${ }^{1}$ which contained factual errors. The statement "Perhaps Vermont's legislators should consider 'may contain' labels for radioisotopes, mercury, cadmium, bird feces, microbial poisons and explosivesingredients that are present in all foods, albeit at undetectable levels" is wrong on two counts. First, it is obviously not possible to know whether these contaminants are present in food if they are, as you state, 'undetectable'. Second, with cadmium, we do know that it is present in easily detectable levels in nonorganic food ${ }^{2}$, as it occurs in significant levels in mined phosphate fertilizers, in particular from Morocco, the source of most phosphate used in non-organic farming in the European Union and also imported into the USA. A recent global meta-analysis found that overall organic food contains at least $50 \%$ less cadmium than non-organic food ${ }^{2}$.
You also mislead your readers about the levels of genetically modified (GM) organism contamination allowed in non-GM food in the European Union when you claim "in ever-so-stringent Europe, legal technicalities mean that "GM-free" foods can still contain up to $0.9 \%$ of GM-derived ingredients." In fact, the European Union (EU; Brussels) labeling law requires zero GM for food not labeled as GM (the lowest reliably detectable level is assumed to be $0.1 \%$, so 'zero' is below that). There is an allowance for exceptional circumstances-accidental contamination or technically unavoidable contaminationwhere up to $0.9 \% \mathrm{GM}$ is allowed before the product must be labeled as GM. This is for one-off, unforeseeable events. Otherwise anything above $0.1 \% \mathrm{GM}$ must be labeled as GM.

You claim that GM labelling would be costly, but an independent review of published studies for the US Consumers' Union by ECONorthwest ${ }^{3}$ found that the median cost of labelling in these studies was $\$ 2.30$ per person per year.

In any event, for those of us living in areas of the world where transparency in food production systems is considered a basic right of citizens, attempts by some in the United States to defend a right of chemical companies and food businesses not to tell their citizens what they are selling them seems bizarre. Free markets clearly cannot work fairly in conditions of secrecy reminiscent of totalitarian states, secrecy that in this case you apparently demand should be enforced by the state in the form of a federal law.

\section{COMPETING FINANCIAL INTERESTS}

The author is an organic farmer in the UK.

\section{Peter Melchett}

Soil Association UK, Bristol, UK. e-mail:pmelchett@soilassociation.org

1. Anonymous. Nat. Biotechnol. 32, 1169 (2014).

2 Barański, M. et al. Br. J. Nutr. 112, 794-811 (2014).

3. Dyke, A. \& Whelan, R. GE foods labeling cost study findings (ECONorthwest, 12 September 2014).

\section{Nature Biotechnology replies:}

The statement "Perhaps Vermont's legislators should consider "may contain" labels for radioisotopes, mercury, cadmium, bird feces, microbial poisons and explosivesingredients that are present in all foods, albeit at undetectable levels" was intended to be ironic. We agree with Peter Melchett that it doesn't make sense to insist on labels for ingredients that are undetectable. The real question is one of relative harm: is the cadmium in 'organic' or 'nonorganic' food more or less beneficial to human health and the environment than the presence or absence of genes altered by one of several methods for altering genes with relative precision (that is, relative to traditional breed-enhancing processes, such as mutation by chemicals or bombardment with radioisotopes)?

We concur with Melchett that had space constraints allowed, a complete description of the European Union's labeling law would have indicated that $0.1 \%$ is the detection threshold; $0.9 \%$ is the threshold "under exceptional circumstances." Nature Biotechnology has no information, however, on how often, in practice, foods with levels of GM ingredients from $0.1 \%$ to $0.9 \%$ are categorized as $\mathrm{GM}$-free.

With regard to the economics of labeling, the report cited by Melchett deals only with the cost of labeling itself and not with the cost of reorganizing agriculture and food processing to create a dual processing 